\title{
Association of low back pain with vitamin $D$ deficiency and other common risk factors: A hospital based case-control study
}

\author{
Ahmed M. S. Hegazy ${ }^{1}$, Basem M. M. Salama ${ }^{2}$, Ahmed M. M. Elgaml ${ }^{3}$, Ahmed Ramzy Alzyat ${ }^{4}$ \\ ${ }^{1}$ Anatomy Department, Benha Faculty of Medicine, Benha University, Benha, Egypt \\ ${ }^{2}$ Community Medicine Department, Damietta Faculty of Medicine, Al-Azhar University, Damietta, Egypt \\ ${ }^{3}$ Clinical Pathology Department, Cairo Faculty of Medicine, Al-Azhar University, Cairo, Egypt \\ ${ }^{4}$ Rheumatology Department, Cairo Faculty of Medicine, Al-Azhar University, Cairo, Egypt
}

Email address:

ahmed0562301954@yahoo.com (A. M. S. Hegazy),DrBasemsalama@yahoo.com (B. M. M. Salama), Lecturest@yahoo.com (A. M. M. Elgaml), Ysalama2005@yahoo.com (A. R. Alzyat)

\section{To cite this article:}

Ahmed M. S. Hegazy, Basem M. M. Salama, Ahmed M. M. Elgaml, Ahmed Ramzy Alzyat. Association of Low Back Pain with Vitamin D Deficiency and other Common Risk Factors: A Hospital Based Case-Control Study. European Journal of Preventive Medicine.

Vol. 3, No. 1, 2015, pp. 1-5. doi: 10.11648/j.ejpm.20150301.11

\begin{abstract}
Background: low back pain (LBP) is an extremely common health Problem in Asian communities. It is a major cause of activity limitation. Aim of this study was to identify the association of vitamin D and modifiable risk factors of low back pain among female patients in the childbearing period. Subject and methods: It was a hospital based case-control approach done at rheumatology and rehabilitation outpatient clinic of Arar hospital in Saudi Arabia during a period of 10 months from September 2010 to June 2011. The study population comprised Saudi female in the childbearing period (2045years) (to exclude rickets in younger females and post menopausal osteoporosis in older ones). Cases were patients who had the complaints of chronic LBP (lasting more than three months) at the time of data collection. For each case, one control was selected from the same age group from patients with no LBP but attend the same units for other reasons. Data were collected with a semi-structured Check list and 174 participants were interviewed from which 87 had back pain (cases). Venous sampling $5 \mathrm{ml}$ was done for both cases and control for serum calcium, phosphate, alkaline phosphatase, PTH and 25- hydroxy cholecalciferol (vitamin D3). Results: Univariate analysis showed that low back pain was significantly associated with age of the patients, low physical activity, body mass index (BMI) $>25 \mathrm{~kg} / \mathrm{m}$, prolonged sitting, history of back trauma ( $\mathrm{p}<0.05$ ). Logistic regression revealed BMI $>25 \mathrm{~kg} / \mathrm{m}$ and hypovitaminosis D as an independent risk factors for low back pain. Conclusion: Low back pain among Saudi female was associated with BMI, physical activity, sitting posture and hypovitaminosis D. All these risk factors could be regarded as the indicators of low back pain, and some relevant preventive measures should be taken to reduce low back pain risk.
\end{abstract}

Keywords: Chronic Low Back Pain (LBP), Low Physical Activity, Vitamin D, Risk Factors

\section{Introduction}

Low back pain (LBP) is one of the most frequent musculoskeletal disorders in daily practice ${ }^{(1)}$. It is defined as pain between the costal margins and inferior gluteal folds and is usually accompanied by painful limitation of movement; it is often influenced by physical activities and posture in most cases ${ }^{(2)}$. People with chronic LBP experience huge social, mental, physical and occupational disruptions ${ }^{(3)}$. The mental impact of LBP includes anxiety, depression and sleeplessness, whilst poor physical performance and deterioration in health status are the physical impacts. LBP results in an inability to carry out social activities and it decreases the capability to perform occupational activities since it mostly affects adults of working age ${ }^{(4)}$. Disability caused by LBP stems from the pain and/or loss of function inflicted on the sufferers. Chronic LBP is one of the four disabilities causing musculoskeletal conditions - the others being osteoarthritis, osteoporosis and rheumatoid arthritis ${ }^{(5)}$.

More than $80 \%$ of the population will experience an 
episode of LBP at some time during their lives. The clinical course is benign for most, with $95 \%$ of those afflicted recovering within a few months of onset. Some, however, will not recover and will develop chronic LBP, i.e. pain that lasts for three months or longer ${ }^{(6)}$.

Risk factors for developing LBP could be immutable (nonmodifiable) or mutable (modifiable). The immutable factors are age, parity, previous history of LBP, whilst the mutable factors include a sedentary lifestyle, obesity, tobacco smoking and drug dependence. Other mutable factors are occupation-related: poor posturing, prolonged sitting, twisting, bending, stooping and lifting of heavy loads ${ }^{(7)}$.

Prolonged chronic vitamin D deficiency can result in osteomalacia; moreover mild vitamin D deficiency may produce a variety of musculoskeletal pains such as fibromyalgia-like pain, low back pain, and arthralgia ${ }^{(8)}$.

This study was carried out to identify the association of vitamin D and modifiable risk factors of low back pain among female patients in the childbearing period in Saudi Arabia.

\section{Subjects and Methods}

Study design and settings: A hospital based case-control approach done at rheumatology and rehabilitation outpatient clinic of Arar Hospital in Saudi Arabia during a period of 10 months from September 2010 to June 2011.

Sampling technique

All Participants who met the study criteria and consented to take part in the study were consecutively selected

Participants and procedure: The study population comprised Saudi female in the childbearing period (2045years) (to exclude rickets in younger females and post menopausal osteoporosis in older ones). Cases were patients who had the complaints of chronic LBP (lasting more than three months) ${ }^{(2)}$ at the time of data collection. For each case, one control was selected from the same age group from patients with no LBP but attend the same units for other reasons (shoulder stiffness, ankle or knee pain or carpal tunnel syndrome, etc.). Total 87 patients were included as cases and 87 patients as controls.

Cases seen initially were assessed clinically for pain and the presence or absence of neurologic manifestation using plain radiograph of the lumbosacral spine. Both CT scanning and MRI of lower spine were performed to exclude disc prolapse, spinal stenosis, and degenerative disease of the spine. These patients were labeled as having idiopathic low back pain after the aforementioned assessment.

Patients who had a mechanical cause for the back pain congenital deformity of the spine, who had Patients clinical features suggestive of neurologic involvement or who had renal impairment or chronic liver disease were excluded from the study.

Venous sampling $5 \mathrm{ml}$ was done for both cases and control for serum calcium, phosphate, alkaline phosphatase, PTH and 25- hydroxy cholecalciferol (vitamin D3). All tests are measured by immunoassay analyzer Cobas e411 and using kits supplied by Roch. Anthropometric measurements of height and weight were carried out for all respondents. The weight (in kilogram) was divided by the height (meter) and then squared to calculate the body mass index (BMI).

Informed consent was obtained from all patients and controls and questionnaire was used to interview the respondents. Information obtained from the respondents consisted of demographic, social, and health related factors; i.e., age, education, employment body mass index (BMI), sun exposure, daily physical activity (low or moderate level) ${ }^{(9)}$, passive smoking (mixture of side stream smoke emitted by lit cigarettes and mainstream smoke exhaled by smokers) ${ }^{(10)}$ and past history of back trauma.

\section{Statistical Analysis}

Data were analyzed by use of SPSS software, version 16.0 (SPSS Inc. Chicago, USA). Univariate analysis was used to compare variables for the outcomes of interest. Continuous data were compared using the Student's t test. Either $\chi 2$ or Fisher's exact tests were used to compare categorical variables. A multivariate analysis was also performed using multiple logistic regressions with enter approach. All $\mathrm{P}$ values lower than 0.05 were considered statistically significant.

\section{Results}

During a 10-month period, Total 174 patients were included in this study 87 as cases (had the complaints of LBP for 3 months or more) and 87 patients as controls (had no LBP ) at the time of data collection.

Table (1) reveals socio- demographic characteristics of the study population:

The mean \pm SD age of patients was $32.8+7.2$ years for the control group and $37.3+5.3$ years for the Cases. The study revealed statistically significant difference between cases and control groups regarding age of the participants ( $p$ $<0.001)$.

There was no significant difference between case and control group with respect to multiparity, education level, occupation, passive smoking, vitamin $\mathrm{D}$ rich food, multiparity and avoiding sun exposure $(\mathrm{P}=0.2,0.2,0.34$, 0.08, 0.06 and 0.07 respectively).

There was significant difference between case and control group regarding physical activity, prolonged sitting, history of back trauma and BMI $>25 \mathrm{~kg} / \mathrm{m}^{2}(\mathrm{P}=0.001,0.02,0.003$ and $<0.001$ respectively).

Table (2) reveals the means of laboratory markers in patients and control

There were no statistically significant differences in mean serum calcium or serum phosphorus between patients and controls $(\mathrm{p}>0.05)$

On the other hand, mean serum ALP, PTH and serum 25 $(\mathrm{OH})$ vitamin $\mathrm{D}$ levels were significantly difference in patients than controls $(\mathrm{p}<0.001)$.

Table (3) shows the logistic regression analysis of the risk 
factors for LBP.

Selected risk factors were entered into a logistic regression revealed that BMI and Serum $25(\mathrm{OH})$ vitamin D were independent risk factors for LBP. model (stepwise) to perform the multivariate analysis which

Table 1. Comparison of socio-demographic between patients and controls.

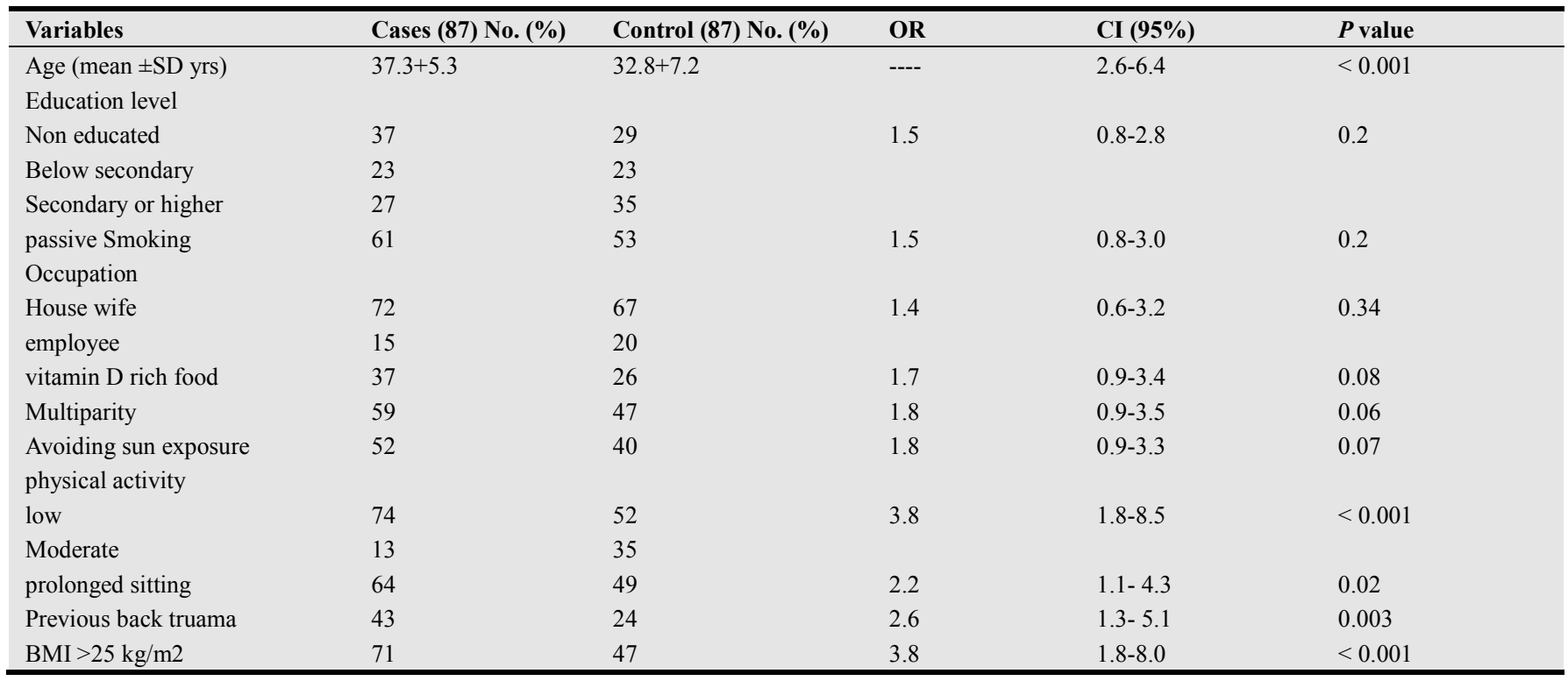

Table 2. Comparison of laboratory markers between patients and controls.

\begin{tabular}{|c|c|c|c|c|}
\hline \multirow{2}{*}{ Variables } & Cases $(n=87)$ & Controls $(n=87)$ & \multirow{2}{*}{$\mathbf{t}$} & \multirow[b]{2}{*}{$\mathbf{p}$} \\
\hline & Mean + SD & Mean + SD & & \\
\hline Serum Calcium $(\mathrm{n} 8.2-10 \mathrm{mg} / \mathrm{dl})$ & $8.9 \pm 1.2$ & $9.1 \pm 0.8$ & 1.37 & 0.2 \\
\hline Phosphorus (n 2.5-4 mg/dl) & $4 \pm 1.1$ & $3.9 \pm 1.0$ & 1.15 & 0.25 \\
\hline${ }^{*} \mathrm{ALP}(\mathrm{n}<136 \mathrm{U} / \mathrm{l})$ & $111.2 \pm 45.4$ & $66.3 \pm 9.2$ & 9.0 & $<0.001$ \\
\hline${ }^{* *}$ PTH $(\mathrm{n}<106 \mathrm{pg} / \mathrm{ml})$ & $147.7 \pm 39.6$ & $20.3 \pm 7.4$ & 29.5 & $<0.001$ \\
\hline Vitamin D $(\mathrm{n}>25 \mathrm{ng} / \mathrm{ml})$ & $21.1 \pm 2.3$ & $31.3 \pm 4.5$ & 18.6 & $<0.001$ \\
\hline
\end{tabular}

*ALP $=$ alkaline phosphatase, $* * \mathrm{PTH}=$ Parathyroid hormone

Table 3. Logistic regression analysis of the risk factors for $L B P$.

\begin{tabular}{llll}
\hline Variables & Adjusted OR & CI (95\%) & P value \\
\hline $\mathrm{BMI}>25 \mathrm{~kg} / \mathrm{m}^{2}$ & 5.6 & $2.4-17.6$ & 0.01 \\
Vitamin D & 3.2 & $1.9-21.2$ & 0.047 \\
\hline
\end{tabular}

\section{Discussion}

Low back pain (LBP) is a common health problem with concomitant disability which has assumed a public health importance in our setting. This study revealed that age was demonstrated to have a significant association with LBP. These results are consistent with previous reports regarding an increased prevalence of LBP with age ${ }^{(11,12)}$. In the elderly Thai population, BMI was identified as a predictive factor for spondylosis of the lower back ${ }^{(13)}$.

Significant association was shown between BMI and LBP. Being overweight or obese causes an increase in the pressure on the structures of the lower back and that may lead to lumbar disc herniation and subsequent LBP. These in agreement with studies reported an association between being overweight and experiencing $\operatorname{LBP}(14,15,16)$. But in contrast to Chung et al. 2005; Grimmer \& Williams 2000 results ${ }^{(17,18)}$
There was no association between regular physical activity and LBP in contrast with previous studies which reported the association between a lack of physical activity and $\operatorname{LBP}{ }^{(19,20)}$

In this study, there was no apparent association between passive smoking and LBP while Miranda et al. (2008) showed an association between smoking and LBP among subjects over 50 yr old.

There was a significant association between a history of back trauma and LBP. Hincapie et al. (2008) ${ }^{(22)}$ showed that a history of work-related low back injury was positively associated with severe disability due to LBP

Prolonged sitting has been identified as a risk factor for LBP. O'Sullivan et al. $2011^{(23)}$ reported that, females and sitting posture was reported as related factors for LBP. The reported consequences of prolonged sitting are increased spinal compression load (24) and increased activity of paraspinal muscles ${ }^{(25)}$. As a result, LBP can occur due to tissue micro-damage and paraspinal muscle dysfunction ${ }^{(26)}$.

Avoiding sunlight exposure was not significantly different among study groups. Sunlight exposure of the skin is known to be the most important source of vitamin D. Under exposure to sunlight is another cause of vitamin D deficiency but overexposure doesn't cause intoxication (27). However, other studies showed that hypovitaminosis D is common 
despite adequate sunshine ${ }^{(28,29)}$.

Among the laboratory parameters, serum 25 OHD was significantly associated with LBP. In study conducted by. These in agreement with studies reported an association between vitamin D deficiency and LBP ${ }^{(30,31)}$. However a few studies have found no association between vitamin D deficiency and musculoskeletal pain ${ }^{(32,33)}$.

Vitamin D is essential for GI absorption of calcium. Vitamin D deficiency results in increased secretion of parathyroid hormone (PTH) which in turn leads to greater than before activity of osteoclasts in bone. Phosphaturic property of PTH with diminished absorption of calcium from GI may reduce calcium-phosphate interaction and consequently bone mineralization. Increased activity of osteoclasts and osteoblasts increases bone matrix with low mineralization. The resultant matrix would absorb water; as a result subperiosteal space becomes edematous. The event may produce bone pain ${ }^{(34)}$.

Conclusion: Low back pain among Saudi female was associated with modifiable factors BMI, physical activity, prolonged sitting and hypovitaminosis D. All these risk factors could be regarded as the indicators of low back pain, and some relevant preventive measures should be taken to reduce low back pain risk.

The limitation of our study is that due to its case control design, so it is susceptible to recall bias. Also small response rate (174 participants) compared to large number of attendants.

\section{References}

[1] Tomita S, Arphorn S, Muto T, Koetkhlai K, Naing SS, Chaikittiporn C. Prevalence and risk factors of low back pain among Thai and Myanmar migrant seafood processing factory workers in Samut Sakorn Province, Thailand. Ind Health. 2010; 48 (3):283-91.

[2] Manek JN, MacGregor AJ: Epidemiology of back disorders: Prevalence, risk factors and prognosis. Curr Opin Rheumatol.2005; 17: 134-140.

[3] Tavafian SS, Jamshidi A, Mohammad K, Montazeri A. Low back pain education and short term quality of life: a randomized trial. BMC Musculoskelet Dis. 2007; 8:21.

[4] Samad N, Abdullah H, Moin S, Tamrin S, Hashim Z. Prevalence of low back pain and its risk factors among school teachers. Am J Appl Sc. 2010; 7(5):634-639.

[5] Louw QA, Morris LD, Grimmer-Somers K. The Prevalence of low back pain in Africa: a systematic review. BMC Musculoskelet Dis. 2007; 8:105.

[6] Freburger JK1, Holmes GM, Agans RP, Jackman AM, Darter JD, Wallace AS, Castel LD, Kalsbeek WD, Carey TS.The rising prevalence of chronic low back pain. Arch Intern Med. 2009; 169(3):251-258.

[7] Vindigni D, Walker BF, Jamison JR, Da Costa C, Parkinson L, Blunden S. Low back pain risk factors in a large rural Australian Aboriginal community. An opportunity for managing co-morbidities? Chirop \& Osteopat. 2005; 13:21.
[8] De Torrenté de la Jara, G., Pécoud, A., \& Favrat, B. Female asylum seekers with musculoskeletal pain: the importance of diagnosis and treatment of hypovitaminosis D. BMC am Pract.2006; 23(7), 4.

[9] Elmahgoub, S. S., Calders, P., Lambers, S., Stegen, S. M., Van Laethem, C., \& Cambier, D. C. (2011). The effect of combined exercise training in adolescents who are overweight or obese with intellectual disability: The role of training frequency. Journal of Strength and Conditioning Research, $25(8), 1$.

[10] Rosen, L.J., Zucker, D.M., Rosen, B.J., Connolly, G.N. Second-hand smoke levels in Israeli bars, pubs and cafes before and after implementation of smoke-free legislation. Eur. J. Public Health 2011, 21, 15-20.

[11] Bernard, J.C., Bard, R., Pujol, A., Combey, A., Boussard, D., Begue, C. \& Salghetti, A.M. Muscle assessment in healthy teenagers, comparison with teenagers with Low back pain. Ann. Readapt. Med. Phy. 2008; 51: 263-283

[12] Poussa, M.S., Heliövaara, M.M., Seitsamo, J.T., Könönen, M.H., Hurmerinta, K.A. \& Nissinen, M.J. Anthropometric measurements and growth as predictors of low back pain: A cohort study of children followed up from the age of 11 to 22 years. Eur. Spine. J. 2005; 14: 595-598.

[13] Chaiwanichsiri D, Jiamworakul A, Jitapunkul S. Lumbar disc degeneration in Thai elderly: a populationbased study. J Med Assoc Thai. 2007; 90, 2477-81.

[14] Omokhodion FO, Sanya AO. Risk factors for low back pain among office workers in Ibadan, Southwest Nigeria. Occup Med. 2003; 53(4):287-289.

[15] Yip YB, Ho SC, Chan SG. Tall stature, overweight and the prevalence of low back pain in Chinese middle-aged women. Int J Obes. 2001; 25(6):887-892.

[16] Heuch I, Heuch I, Hagen K, Zwart JA. Body mass index as a risk factor for developing chronic low back pain: a follow-up in the Nord-Trøndelag Health Study. Spine (Phila Pa 1976). 2013; 38(2):133-9.

[17] Chung, Y.L., Kratter, R., Duvoisin, N., Taskin, N.D.A. \& Schilling, J. Cross-sectional view of factors associated with back pain. Int. Arch. Occup. Environ. Health. 2005; 78: 319 324

[18] Grimmer, K. \& Williams, K. Gender-age environment associates of adolescent low back pain. Appl. Ergon. 2000; 31:343-360.

[19] Bjorck-van Dijken C, Fjellman-Wiklund A, Hildingsson C. Low back pain, lifestyle factors and physical activity: a population based-study. J Rehabil Med. 2008; 40, 864-9.

[20] Nagasu M, Sakai K, Ito A, Tomita S, Temmyo Y, Ueno M, Miyagi S. Prevalence and risk factors for low back pain among professional cooks working in school lunch services. BMC Public Health. 2007; 7, 171.

[21] Miranda H, Viikari-Juntura E, Punnett L, Riihimaki H. Occupational loading, health behavior and sleep disturbance as predictors of low-back pain. Scand JWork Environ Health. 2008; 34, 411-9.

[22] Hincapie CA, Cassidy JD, Cote P (Is a history of work-related low back injury associated with prevalent low back pain and depression in the general population? BMC Musculoskelet Disord. 2008; 9, 22. 
[23] O’Sullivan, P.B., Smith, A.J., Beales, D.J. \& Straker, L.M. Association of biopsychosocial factors with degree of slump in sitting posture and self-report of back pain in adolescents: A cross-sectional study. Phys. Ther. 2011; 91(4): 470-483.

[24] Callaghan, J.P. \& McGill, S.M. Low back joint loading and kinematics during standing and unsupported sitting. Ergon. 2001; 44: 280-294.

[25] Harrison, D.D., Harrison, S.O., Croft, A.C., Harrison, D.E. \& Troyanovich, S.J. Sitting biomechanics part I: Review of the literature. J. Manip. Physiol. Ther. 1999; 22: 594-609.

[26] Solomonow, M., Bratta, R.V., Zhou, B.H., Burger, E., Zieske, A. \& Gedalia, A. Muscular dysfunction elicited by creep of lumbar viscoelastic tissue. J. Electromyogr. Kinesiol. 2003; 13: 381-396.

[27] Holick, M. F. Vitamin D deficiency: what a pain it is. Mayo Clin Proc, 2003; 78(12), 1457-9.

[28] Moussavi M, Heidarpur R, Aminorroaya A, Pournaghshband Z, Amini M. Prevalence of vitamin D deficiency in Isfahani high school students in 2004. Horm Res. 2005; 64:144-148.

[29] Meddeb N, Sahli H, Chahed M et al. Vitamin D deficiency in Tunisia. Osteoporos Int. 2005; 16:180-183.
[30] Heidari, B., Shirvani, J. S., Firouzjahi, A., Heidari, P., \& Hajian-Tilaki, K. O. Association between nonspecific skeletal pain and vitamin D deficiency. Int J Rheum Dis. 2010; 13(4), 340-6.

[31] e Silva AV, Lacativa PG, Russo LA, de Gregório LH, Pinheiro RA, Marinheiro LP. Association of back pain with hypovitaminosis D in postmenopausal women with low bone mass. BMC Musculoskelet Disord. 2013; 12;140-184.

[32] Block, S. R.Vitamin D deficiency is not associated with nonspecific musculoskeletal pain syndromes including fibromyalgia. Mayo Clin Proc. 2004; 79(12), 1585-6.

[33] Warner, A. E., \& Arnspiger, S. A. Diffuse musculoskeletal pain is not associated with low vitamin D levels or improved by treatment with vitamin D. J Clin Rheumatol, 2008;14(1), $12-6$.

[34] Holick MF, Garabedian M. Vitamin D: photobiology, metabolism, mechanism of action, and clinical applications. In Favus MJ, ed. Primer on the metabolic bone diseases and disorders of mineral metabolism. 6th ed. Washington, DC: American Society for Bone and Mineral Research, 2006:129- 